\title{
$\alpha-\psi$-Geraghty contractions on generalized metric spaces
}

Mehdi Asadi ${ }^{1}$, Erdal Karapınar ${ }^{2,3}$ and Anil Kumar ${ }^{4,5 *}$

Dedicated to Professor Shih-sen Chang on the occasion of his 80th birthday.

"Correspondence:

anilkshk84@gmail.com

${ }^{4}$ Department of Mathematics,

Maharshi Dayanand University,

Rohtak, Haryana 124001, India

${ }^{5}$ Department of Mathematics, Govt.

College Nagina, Mewat, Haryana

122108, India

Full list of author information is

available at the end of the article

\begin{abstract}
In this work, we introduce the class of $\alpha$ - $\psi$-Geraghty contraction as well as generalized $\alpha-\psi$-Geraghty contraction mappings in the context of generalized metric spaces where $\psi$ is an auxiliary function which does not require the subadditive property and set up some fixed point results for both classes individually. Our results will extend, improve and generalize several existing results in the literature. MSC: $46 \mathrm{~T} 99 ; 47 \mathrm{H} 10 ; 54 \mathrm{H} 25$
\end{abstract}

Keywords: generalized metric spaces; $\alpha-\psi$ contractions

\section{Introduction}

Fixed point theory focuses on the strategies for solving nonlinear equations of kind $T x=x$, where the function $T$ is defined on some abstract space $X$. It is well known that the classical contraction mapping principal of Banach is one of the most useful and fundamental results in the theory of fixed point. It guarantees the existence and uniqueness of fixed points for certain self-maps in a complete metric space and provides a constructive method to find those fixed points. Due to its practical implication, several authors studied and extended it in many directions; for example, see [1-50] and the references therein.

In 1973, Geraghty [33] introduced an interesting class of auxiliary functions to refine the Banach contraction mapping principle. Let $\mathcal{F}$ denote all functions $\beta:[0, \infty) \rightarrow[0,1)$ which satisfy the condition

$$
\lim _{n \rightarrow \infty} \beta\left(t_{n}\right)=1 \text { implies } \quad \lim _{n \rightarrow \infty} t_{n}=0 .
$$

By using the function $\beta \in \mathcal{F}$, Geraghty [33] proved the following remarkable theorem.

Theorem 1 (Geraghty [33]) Let $(X, d)$ be a complete metric space and $T: X \rightarrow X$ be an operator. Suppose that there exists $\beta:[0, \infty) \rightarrow[0,1)$ satisfying the condition

$$
\beta\left(t_{n}\right) \rightarrow 1 \text { implies } t_{n} \rightarrow 0 .
$$

If $T$ satisfies the following inequality

$$
d(T x, T y) \leq \beta(d(x, y)) d(x, y) \quad \text { for any } x, y \in X,
$$

then T has a unique fixed point.

\section{Springer}

(c) 2014 Asadi et al.; licensee Springer. This is an Open Access article distributed under the terms of the Creative Commons Attribution License (http://creativecommons.org/licenses/by/2.0), which permits unrestricted use, distribution, and reproduction in any medium, provided the original work is properly cited. 
On the other hand, Branciari [1] made an attempt to generalize the Banach contraction principle by bringing out the notion of generalized metric, as well known as rectangular metric, where he replaced the triangle inequality with the weaker assumption, namely, quadrilateral inequality. The space $X$ equipped with generalized metric or rectangular metric became known as generalized metric space or rectangular space. Afterward, several authors studied these spaces and provided various fixed point results in such spaces (see, e.g., $[2,5-13,46]$ ).

Recently, Samet et al. [14] introduced the class of $\alpha-\psi$ contractive type mappings and obtained a fixed point result for this new class of mappings in the set up of a metric space which properly contains several well-known fixed point theorems including the Banach contraction principle. The technique used in this paper has been studied and improved by a number of authors (see, e.g., [15-20, 42-47]).

In this paper, we introduce two notions viz. $\alpha-\psi$-Geraghty contraction mappings and generalized $\alpha-\psi$-Geraghty contraction mappings and investigate the existence and uniqueness of fixed points for both classes in the setting of a generalized metric space, where $\psi$ is an auxiliary function which does not require the subadditive property.

\section{Preliminaries}

In this section, we recall some useful definitions and auxiliary results that will be needed in the sequel. Throughout this paper, $\mathbb{N}$ and $\mathbb{R}$ denote the set of natural numbers and the set of real numbers, respectively.

Definition 2 [1] Let $X$ be a nonempty set, and let $d: X \times X \rightarrow[0, \infty]$ satisfy the following conditions for all $x, y \in X$ and all distinct $u, v \in X$ each of which is different from $x$ and $y$,

(GM1) $d(x, y)=0$ if and only if $x=y$,

(GM2) $d(x, y)=d(y, x)$,

(GM3) $\quad d(x, y) \leq d(x, u)+d(u, v)+d(v, y)$.

Then the map $d$ is called generalized metric and abbreviated as GM. Here, the pair $(X, d)$ is called generalized metric space and abbreviated as GMS. Given a generalized metric $d$ on $X$ and $\epsilon>0$, we call $B_{d}(x, \epsilon)=\{y \in X \mid d(x, y)<\epsilon\} \epsilon$-ball centered at $x$.

In the above definition, the expression (GM3) is called quadrilateral inequality. Notice also that if $d$ satisfies only (GM1) and (GM2), then it is called semimetric (see, e.g., [3]).

\section{Remark 3}

(1) Any metric space is generalized metric space, but the converse is not true in general, as shown in $[1,8,12]$.

(2) In [1], it was taken for granted that a generalized metric space is a Hausdorff topological space and as in a metric space, the topology of a generalized metric space can be generated by the collection of all $\epsilon$-balls $B_{d}(x, \epsilon)$ for $x \in X$ and $\epsilon>0$. But Das and Lahiri [7] showed that these assumptions are not true in an arbitrary generalized metric space (see [7, Example 1 and Example 2]). Nevertheless, it is to be observed that the GMS $(X, d)$ becomes a topological space when a subset $U$ of $X$ is said to be open if to each $a \in U$, there exists a positive number $\epsilon_{a}$ such that 
$B_{d}\left(a, \epsilon_{a}\right) \subseteq U$. For a useful discussion on the topological structure of GMS, one can refer to [28].

The concepts of convergence, Cauchy sequence, completeness and continuity on a GMS are defined below.

\section{Definition 4}

(1) A sequence $\left\{x_{n}\right\}$ in a GMS $(X, d)$ is GMS convergent to a limit $x$ if and only if $d\left(x_{n}, x\right) \rightarrow 0$ as $n \rightarrow \infty$.

(2) A sequence $\left\{x_{n}\right\}$ in a GMS $(X, d)$ is GMS Cauchy if and only if for every $\epsilon>0$ there exists a positive integer $N(\epsilon)$ such that $d\left(x_{n}, x_{m}\right)<\epsilon$ for all $n>m>N(\epsilon)$.

(3) A GMS $(X, d)$ is called complete if every GMS Cauchy sequence in $X$ is GMS convergent.

(4) A mapping $T:(X, d) \rightarrow(X, d)$ is continuous if for any sequence $\left\{x_{n}\right\}$ in $X$ such that $d\left(x_{n}, x\right) \rightarrow 0$ as $n \rightarrow \infty$, we have $d\left(T x_{n}, T x\right) \rightarrow 0$ as $n \rightarrow \infty$.

Lemma 5 [46, Lemma 1] Let $(X, d)$ be a generalized metric space, and let $\left\{x_{n}\right\}$ be a Cauchy sequence in $X$ such that $x_{m} \neq x_{n}$ whenever $m \neq n$. Then $\left\{x_{n}\right\}$ can converge to at most one point.

Lemma 6 [46] Let $(X, d)$ be a generalized metric space, and let $\left\{x_{n}\right\}$ be a sequence in $X$ with distinct elements $\left(x_{n} \neq x_{m}\right.$ for $\left.n \neq m\right)$. Suppose that $d\left(x_{n}, x_{n+1}\right)$ and $d\left(x_{n}, x_{n+2}\right)$ tend to 0 as $n \rightarrow \infty$ and that $\left\{x_{n}\right\}$ is not a Cauchy sequence. Then there exist $\epsilon>0$ and two sequences $\left\{m_{k}\right\}$ and $\left\{n_{k}\right\}$ of positive integers such that $n_{k}>m_{k}>k$ and the following four sequences

$$
d\left(x_{m_{k}}, x_{n_{k}}\right), \quad d\left(x_{m_{k}}, x_{n_{k+1}}\right), \quad d\left(x_{m_{k-1}}, x_{n_{k}}\right), \quad d\left(x_{m_{k-1}}, x_{n_{k+1}}\right)
$$

tend to $\epsilon$ as $k \rightarrow \infty$.

Proposition 7 [5] Suppose that $\left\{x_{n}\right\}$ is a Cauchy sequence in a GMS $(X, d)$ with

$$
\lim _{n \rightarrow \infty} d\left(x_{n}, u\right)=0,
$$

where $u \in X$. Then $\lim _{n \rightarrow \infty} d\left(x_{n}, z\right)=d(u, z)$ for all $z \in X$.

Samet et al. [14] introduced the notion of $\alpha$-admissible mappings as follows.

Definition 8 Let $X$ be a nonempty set, and let $T: X \rightarrow X$ and $\alpha: X \times X \rightarrow[0, \infty)$ be mappings. Then $T$ is called $\alpha$-admissible if for all $x, y \in X$, we have

$$
\alpha(x, y) \geq 1 \quad \Rightarrow \quad \alpha(T x, T y) \geq 1 .
$$

Some interesting examples of such mappings are given in [14]. Afterward, several authors (see, e.g., $[25,26,38-41]$ ) studied such mappings and used them to prove some interesting results in fixed point theory.

Recently, Karapinar et al. [42] defined the notion of triangular $\alpha$-admissible mappings as follows. 
Definition 9 Let $X$ be a nonempty set, and let $T: X \rightarrow X$ and $\alpha: X \times X \rightarrow \mathbb{R}$ be mappings. Then $T$ is called triangular $\alpha$-admissible if

(1) $x, y \in X, \alpha(x, y) \geq 1 \Rightarrow \alpha(T x, T y) \geq 1$;

(2) $x, y, z \in X, \alpha(x, z) \geq 1$ and $\alpha(y, z) \geq 1 \Rightarrow \alpha(x, y) \geq 1$.

Lemma 10 [42] Let $T: X \rightarrow X$ be a triangular $\alpha$-admissible map. Assume that there exists $x_{1} \in X$ such that $\alpha\left(x_{1}, T x_{1}\right) \geq 1$. Define a sequence $\left\{x_{n}\right\}$ by $x_{n+1}=T x_{n}$. Then we have $\alpha\left(x_{n}, x_{m}\right) \geq 1$ for all $m, n \in \mathbb{N}$ with $n<m$.

Now, we define the following class of auxiliary functions which will be used densely in the sequel. Let $\Psi$ denote the class of functions $\psi:[0, \infty) \rightarrow[0, \infty)$ which satisfy the following conditions:

(a) $\psi$ is nondecreasing;

(b) $\psi$ is continuous;

(c) $\psi(t)=0 \Leftrightarrow t=0$.

It is important to note that this work contains the fixed point results for $\alpha-\psi$-Geraghty contraction and generalized $\alpha-\psi$-Geraghty contraction mappings which are proved by keeping in view the fact that a generalized metric space need not be continuous, neither the respective topology needs to be Hausdorff and also the auxiliary function $\psi$ defined above omits the assumption of subadditive property used in [47].

\section{Main results}

We start this section with the following definition.

Definition 11 Let $(X, d)$ be a generalized metric space, and let $\alpha: X \times X \rightarrow \mathbb{R}$ be a function. A map $T: X \rightarrow X$ is called $\alpha-\psi$-Geraghty contraction mapping if there exists $\beta \in \mathcal{F}$ such that for all $x, y \in X$,

$$
\alpha(x, y) \psi(d(T x, T y)) \leq \beta(\psi(d(x, y))) \psi(d(x, y))
$$

where $\psi \in \Psi$.

Note that if we take $\psi(t)=t$ in Definition 11, then $T$ is called $\alpha$-Geraghty contraction mapping. Again, if we take $\alpha(x, y)=1$ for all $x, y \in X$ in Definition 11, then $T$ is called $\psi$-Geraghty contraction mapping.

Theorem 12 Let $(X, d)$ be a complete generalized metric space, $\alpha: X \times X \rightarrow \mathbb{R}$ be a function, and let $T: X \rightarrow X$ be a map. Suppose that the following conditions are satisfied:

(1) $T$ is an $\alpha-\psi$-Geraghty contraction mapping;

(2) $T$ is triangular $\alpha$-admissible;

(3) there exists $x_{0} \in X$ such that $\alpha\left(x_{0}, T x_{0}\right) \geq 1$ and $\alpha\left(x_{0}, T^{2} x_{0}\right) \geq 1$;

(4) $T$ is continuous.

Then $T$ has a fixed point $x^{*} \in X$, and $\left\{T^{n} x_{0}\right\}$ converges to $x^{*}$.

Proof By (3) let $x_{0} \in X$, construct the sequence $\left\{x_{n}\right\}$ as $x_{n+1}=T x_{n}, n \in \mathbb{N}$. If $x_{n}=x_{n+1}$ for some $n \in \mathbb{N} \cup\{0\}$, then $x^{*}=x_{n}$ is a fixed point of $T$. Assume further that $x_{n} \neq x_{n+1}$ for each 
$n \in \mathbb{N} \cup\{0\}$. Since $T$ is triangular $\alpha$-admissible, it follows from (3) that

$$
\alpha\left(x_{1}, x_{2}\right)=\alpha\left(x_{1}, T x_{1}\right) \geq 1 \quad \text { and } \quad \alpha\left(x_{1}, x_{3}\right)=\alpha\left(x_{1}, T^{2} x_{1}\right) \geq 1 .
$$

Due to Lemma 10, we have

$$
\alpha\left(x_{n}, x_{n+1}\right) \geq 1 \quad \text { and } \quad \alpha\left(x_{n}, x_{n+2}\right) \geq 1
$$

for all $n \in \mathbb{N}$. Notice that we also find $\alpha\left(x_{n}, x_{n+m}\right) \geq 1$ for each $m, n \in \mathbb{N}$.

Now, we shall prove that $\lim _{n \rightarrow \infty} d\left(x_{n}, x_{n+1}\right)=0$. By taking $x=x_{n-1}$ and $y=x_{n}$ in (3.1) and regarding (3.2), we get that

$$
\begin{aligned}
\psi\left(d\left(x_{n}, x_{n+1}\right)\right) & \leq \alpha\left(x_{n-1}, x_{n}\right) \psi\left(d\left(T x_{n-1}, T x_{n}\right)\right) \\
& \leq \beta\left(\psi\left(d\left(x_{n-1}, x_{n}\right)\right)\right) \psi\left(d\left(x_{n-1}, x_{n}\right)\right) \\
& <\psi\left(d\left(x_{n-1}, x_{n}\right)\right)
\end{aligned}
$$

for each $n \in \mathbb{N}$.

Since $\psi$ is nondecreasing, we conclude from (3.3) that

$$
d\left(x_{n}, x_{n+1}\right)<d\left(x_{n-1}, x_{n}\right)
$$

for each $n \in \mathbb{N}$. Thus, we conclude that the sequence $\left\{d\left(x_{n}, x_{n+1}\right)\right\}$ is nonnegative and nonincreasing. As a result, there exists $r \geq 0$ such that $\lim _{n \rightarrow \infty} d\left(x_{n}, x_{n+1}\right)=r$. We claim that $r=0$. Suppose, on the contrary, that $r>0$. Then, on account of (3.3), we get that

$$
\frac{\psi\left(d\left(x_{n}, x_{n+1}\right)\right)}{\psi\left(d\left(x_{n-1}, x_{n}\right)\right)} \leq \beta\left(\psi\left(d\left(x_{n-1}, x_{n}\right)\right)\right)<1,
$$

which yields that $\lim _{n \rightarrow \infty} \beta\left(\psi\left(d\left(x_{n}, x_{n+1}\right)\right)\right)=1$. We derive

$$
\lim _{n \rightarrow \infty} \psi\left(d\left(x_{n}, x_{n+1}\right)\right)=0 \text {, }
$$

due to the fact that $\beta \in \mathcal{F}$. On the other hand, the continuity of $\psi$ together with (3.4) yields that

$$
r=\lim _{n \rightarrow \infty} d\left(x_{n}, x_{n+1}\right)=0
$$

Analogously, we shall prove that $\lim _{n \rightarrow \infty} d\left(x_{n}, x_{n+2}\right)=0$. By substituting $x=x_{n-1}$ and $y=x_{n+1}$ in (3.1) and taking (3.2) into account, we find that

$$
\begin{aligned}
\psi\left(d\left(x_{n}, x_{n+2}\right)\right) & \leq \alpha\left(x_{n-1}, x_{n+1}\right) \psi\left(d\left(T x_{n-1}, T x_{n+1}\right)\right) \\
& \leq \beta\left(\psi\left(d\left(x_{n-1}, x_{n+1}\right)\right)\right) \psi\left(d\left(x_{n-1}, x_{n+1}\right)\right) \\
& <\psi\left(d\left(x_{n-1}, x_{n+1}\right)\right)
\end{aligned}
$$

for each $n \in \mathbb{N}$. Since $\psi$ is nondecreasing, we derive from (3.6) that

$$
d\left(x_{n}, x_{n+2}\right)<d\left(x_{n-1}, x_{n+1}\right)
$$


for each $n \in \mathbb{N}$. Thus, we observe that the sequence $\left\{d\left(x_{n-1}, x_{n+1}\right)\right\}$ is nonnegative and nonincreasing. Consequently, there exists $r \geq 0$ such that $\lim _{n \rightarrow \infty} d\left(x_{n-1}, x_{n+1}\right)=r$. We assert that $r=0$. Suppose, on the contrary, that $r>0$. Then, by regarding (3.6), we get that

$$
\frac{\psi\left(d\left(x_{n}, x_{n+2}\right)\right)}{\psi\left(d\left(x_{n-1}, x_{n+1}\right)\right)} \leq \beta\left(\psi\left(d\left(x_{n-1}, x_{n+1}\right)\right)\right)<1,
$$

which implies that $\lim _{n \rightarrow \infty} \beta\left(\psi\left(d\left(x_{n-1}, x_{n+1}\right)\right)\right)=1$. We derive

$$
\lim _{n \rightarrow \infty} \psi\left(d\left(x_{n-1}, x_{n+1}\right)\right)=0,
$$

due to the fact that $\beta \in \mathcal{F}$. On the other hand, the continuity of $\psi$ together with (3.7) yields that

$$
r=\lim _{n \rightarrow \infty} d\left(x_{n-1}, x_{n+1}\right)=0=\lim _{n \rightarrow \infty} d\left(x_{n}, x_{n+2}\right) .
$$

Suppose that $x_{n}=x_{m}$ for some $m, n \in \mathbb{N}, m<n$. Then

$$
\begin{aligned}
\psi\left(d\left(x_{m}, x_{m+1}\right)\right) & =\psi\left(d\left(x_{n}, x_{n+1}\right)\right) \\
& \leq \beta\left(\psi\left(d\left(x_{n-1}, x_{n}\right)\right)\right) \psi\left(d\left(x_{n-1}, x_{n}\right)\right) \\
& <\psi\left(d\left(x_{n-1}, x_{n}\right)\right) \\
& \leq \psi^{n-m}\left(d\left(x_{m}, x_{m+1}\right)\right) \\
& <\psi\left(d\left(x_{m}, x_{m+1}\right)\right)
\end{aligned}
$$

a contradiction. Hence, all elements of the sequence $\left\{x_{n}\right\}$ are distinct.

We are ready to prove that $\left\{x_{n}\right\}$ is a Cauchy sequence in $(X, d)$. Suppose, on the contrary, that we have

$$
\epsilon=\limsup _{m, n \rightarrow \infty} d\left(x_{n}, x_{m}\right)>0 .
$$

Regarding the quadrilateral inequality, we need to examine two possible cases as follows.

Case 1. Suppose that $k=n-m$ is odd, where $k \geq 1$. Then we have

$$
\begin{aligned}
d\left(x_{n}, x_{m}\right) & \leq d\left(x_{n}, x_{n+1}\right)+d\left(x_{n+1}, x_{m+1}\right)+d\left(x_{m+1}, x_{m}\right) \\
& =d\left(x_{n}, x_{n+1}\right)+d\left(T x_{n}, T x_{m}\right)+d\left(x_{m+1}, x_{m}\right),
\end{aligned}
$$

which is equivalent to

$$
d\left(x_{n}, x_{m}\right)-d\left(x_{n}, x_{n+1}\right)-d\left(x_{m+1}, x_{m}\right) \leq d\left(T x_{n}, T x_{m}\right) .
$$

Since $T$ is triangular $\alpha$-admissible, by applying $\psi$, we get that

$$
\begin{aligned}
& \psi\left(d\left(x_{n}, x_{m}\right)-d\left(x_{n}, x_{n+1}\right)-d\left(x_{m+1}, x_{m}\right)\right) \\
& \quad \leq \psi\left(d\left(T x_{n}, T x_{m}\right)\right)
\end{aligned}
$$




$$
\begin{aligned}
& \leq \alpha\left(x_{n}, x_{m}\right) \psi\left(d\left(T x_{n}, T x_{m}\right)\right) \\
& \leq \beta\left(\psi\left(d\left(x_{n}, x_{m}\right)\right)\right) \psi\left(d\left(x_{n}, x_{m}\right)\right) .
\end{aligned}
$$

Letting $m, n \rightarrow \infty$, we deduce that

$$
\begin{aligned}
& \lim _{m, n \rightarrow \infty} \psi\left(d\left(x_{n}, x_{m}\right)-d\left(x_{n}, x_{n+1}\right)-d\left(x_{m+1}, x_{m}\right)\right) \\
& \leq \lim _{m, n \rightarrow \infty} \beta\left(\psi\left(d\left(x_{n}, x_{m}\right)\right)\right) \lim _{m, n \rightarrow \infty} \psi\left(d\left(x_{m}, x_{n}\right)\right) .
\end{aligned}
$$

So, by using (3.5), (3.9) and the continuity of $\psi$, we get

$$
1 \leq \lim _{m, n \rightarrow \infty} \beta\left(\psi\left(d\left(x_{n}, x_{m}\right)\right)\right)
$$

which implies $\lim _{m, n \rightarrow \infty} \beta\left(\psi\left(d\left(x_{n}, x_{m}\right)\right)\right)=1$. Consequently, we get $\lim _{m, n \rightarrow \infty} d\left(x_{n}, x_{m}\right)=0$, which is a contradiction.

Case 2. Suppose that $k=n-m$ is even, where $k \geq 1$. So, we have

$$
\begin{aligned}
d\left(x_{n}, x_{m}\right) & \leq d\left(x_{n}, x_{n+2}\right)+d\left(x_{n+2}, x_{m+2}\right)+d\left(x_{m+2}, x_{m}\right) \\
& =d\left(x_{n}, x_{n+2}\right)+d\left(T x_{n+1}, T x_{m+1}\right)+d\left(x_{m+2}, x_{m}\right),
\end{aligned}
$$

that can be written as

$$
d\left(x_{n}, x_{m}\right)-d\left(x_{n}, x_{n+2}\right)-d\left(x_{m+2}, x_{m}\right) \leq d\left(T x_{n+1}, T x_{m+1}\right) .
$$

Due to the fact that $T$ is triangular $\alpha$-admissible, by applying $\psi$, we obtain that

$$
\begin{aligned}
& \psi\left(d\left(x_{n}, x_{m}\right)-d\left(x_{n}, x_{n+2}\right)-d\left(x_{m+2}, x_{m}\right)\right) \\
& \quad \leq \psi\left(d\left(T x_{n+1}, T x_{m+1}\right)\right) \\
& \quad \leq \alpha\left(x_{n+1}, x_{m+1}\right) \psi\left(d\left(T x_{n+1}, T x_{m+1}\right)\right) \\
& \quad \leq \beta\left(\psi\left(d\left(x_{n+1}, x_{m+1}\right)\right)\right) \psi\left(d\left(x_{n+1}, x_{m+1}\right)\right) .
\end{aligned}
$$

Letting $m, n \rightarrow \infty$, we find that

$$
\begin{aligned}
& \lim _{m, n \rightarrow \infty} \psi\left(d\left(x_{n}, x_{m}\right)-d\left(x_{n}, x_{n+2}\right)-d\left(x_{m+2}, x_{m}\right)\right) \\
& \leq \lim _{m, n \rightarrow \infty} \beta\left(\psi\left(d\left(x_{n+1}, x_{m+1}\right)\right)\right) \lim _{m, n \rightarrow \infty} \psi\left(d\left(x_{n+1}, x_{m+1}\right)\right) .
\end{aligned}
$$

So, by using (3.8), (3.9) and the continuity of $\psi$, we observe

$$
1 \leq \lim _{m, n \rightarrow \infty} \beta\left(\psi\left(d\left(x_{n+1}, x_{m+1}\right)\right)\right)
$$

which yields $\lim _{m, n \rightarrow \infty} \beta\left(\psi\left(d\left(x_{n+1}, x_{m+1}\right)\right)\right)=1$. Thus, we conclude that $\lim _{m, n \rightarrow \infty} d\left(x_{n+1}\right.$, $\left.x_{m+1}\right)=0$, which is a contradiction. 
From Case 1 and Case 2 we concluded that $\left\{x_{n}\right\}$ is a Cauchy sequence. Since $(X, d)$ is a complete generalized metric space, there exists $x^{*} \in X$ such that $\lim _{n \rightarrow \infty} d\left(x_{n}, x^{*}\right)=0$. Since $T$ is continuous, we have

$$
\lim _{n \rightarrow \infty} d\left(T x_{n}, x^{*}\right)=\lim _{n \rightarrow \infty} d\left(x_{n+1}, T x^{*}\right)=0 .
$$

By Lemma 5, we have that $T x^{*}=x^{*}$.

If we let $\psi(t)=t$ in Theorem 12, we get the following result.

Corollary 13 Let $(X, d)$ be a complete generalized metric space, $\alpha: X \times X \rightarrow \mathbb{R}$ be a function, and let $T: X \rightarrow X$ be a map. Suppose that the following conditions are satisfied:

(1) $T$ is an $\alpha$-Geraghty contraction mapping;

(2) $T$ is triangular $\alpha$-admissible;

(3) there exists $x_{0} \in X$ such that $\alpha\left(x_{0}, T x_{0}\right) \geq 1$ and $\alpha\left(x_{0}, T^{2} x_{0}\right) \geq 1$;

(4) $T$ is continuous

Then $T$ has a fixed point $x^{*} \in X$, and $\left\{T^{n} x_{0}\right\}$ converges to $x^{*}$.

It is also possible to remove the continuity of the mapping $T$ by replacing a weaker condition.

Definition 14 Let $(X, d)$ be a complete generalized metric space, $\alpha: X \times X \rightarrow \mathbb{R}$ be a function, and let $T: X \rightarrow X$ be a map. We say that the sequence $\left\{x_{n}\right\}$ is $\alpha$-regular, the following condition is satisfied:

If $\left\{x_{n}\right\}$ is a sequence in $X$ such that $\alpha\left(x_{n}, x_{n+1}\right) \geq 1$ for all $n$ and $x_{n} \rightarrow x \in X$ as

$n \rightarrow+\infty$, then there exists a subsequence $\left\{x_{n_{k}}\right\}$ of $\left\{x_{n}\right\}$ such that $\alpha\left(x_{n_{k}}, x\right) \geq 1$ for all $k$.

Theorem 15 Let $(X, d)$ be a complete generalized metric space, $\alpha: X \times X \rightarrow \mathbb{R}$ be a function, and let $T: X \rightarrow X$ be a map. Suppose that the following conditions are satisfied:

(1) $T$ is an $\alpha-\psi$-Geraghty contraction mapping;

(2) $T$ is triangular $\alpha$-admissible;

(3) there exists $x_{0} \in X$ such that $\alpha\left(x_{0}, T x_{0}\right) \geq 1$ and $\alpha\left(x_{0}, T^{2} x_{0}\right) \geq 1$;

(4) either $T$ is continuous or $\left\{x_{n}\right\}$ is $\alpha$-regular.

Then $T$ has a fixed point $x^{*} \in X$, and $\left\{T^{n} x_{0}\right\}$ converges to $x^{*}$.

Proof Following the proof of Theorem 12, we know that the sequence $\left\{x_{n}\right\}$, defined by $x_{n+1}=T x_{n}$ for all $n \geq 0$, converges to some $x^{*} \in X$. From (3.2) and assumption (4) of the theorem, there exists a subsequence $\left\{x_{n_{k}}\right\}$ of $\left\{x_{n}\right\}$ such that $\alpha\left(x_{n_{k}}, x^{*}\right) \geq 1$ Applying (3.1), for all $k$, we get that

$$
\begin{aligned}
\psi\left(d\left(x_{n_{k+1}}, T x^{*}\right)\right) & \leq \alpha\left(x_{n_{k}}, x^{*}\right) \psi\left(d\left(T x_{n_{k}}, T x^{*}\right)\right) \\
& \leq \beta\left(\psi\left(d\left(x_{n_{k}}, x^{*}\right)\right)\right) \psi\left(d\left(x_{n_{k}}, x^{*}\right)\right) \\
& <\psi\left(d\left(x_{n_{k}}, x^{*}\right)\right) .
\end{aligned}
$$

After letting $k \rightarrow \infty$ in (3.16), we have

$$
\lim _{k \rightarrow \infty} \psi\left(d\left(x_{n_{k+1}}, T x^{*}\right)\right) \leq 0
$$

Therefore, in view of Proposition 7 , we can say $x^{*}=T x^{*}$. 
The following result can be derived from Theorem 15 by letting $\psi(t)=t$.

Corollary 16 Let $(X, d)$ be a complete generalized metric space, $\alpha: X \times X \rightarrow \mathbb{R}$ be a function, and let $T: X \rightarrow X$ be a map. Suppose that the following conditions are satisfied:

(1) $T$ is an $\alpha$-Geraghty contraction mapping;

(2) $T$ is triangular $\alpha$-admissible;

(3) there exists $x_{0} \in X$ such that $\alpha\left(x_{0}, T x_{0}\right) \geq 1$ and $\alpha\left(x_{0}, T^{2} x_{0}\right) \geq 1$;

(4) either $T$ is continuous or $\left\{x_{n}\right\}$ is $\alpha$-regular.

Then $T$ has a fixed point $x^{*} \in X$, and $\left\{T^{n} x_{0}\right\}$ converges to $x^{*}$.

Now we introduce the notion of generalized $\alpha-\psi$-Geraghty contraction.

Definition 17 Let $(X, d)$ be a generalized metric space, and let $\alpha: X \times X \rightarrow \mathbb{R}$ be a function. A map $T: X \rightarrow X$ is called generalized $\alpha-\psi$-Geraghty contraction mapping if there exists $\beta \in \mathcal{F}$ such that for all $x, y \in X$,

$$
\alpha(x, y) \psi(d(T x, T y)) \leq \beta(\psi(M(x, y))) \psi(M(x, y)),
$$

where $M(x, y)=\max \{d(x, y), d(x, T x), d(y, T y)\}$ and $\psi \in \Psi$.

Note that if we take $\psi(t)=t$ in the above definition, then $T$ is called generalized $\alpha$-Geraghty contraction mapping. Again, if we take $\alpha(x, y)=1$ for all $x, y \in X$, then $T$ is called generalized $\psi$-Geraghty contraction mapping.

Theorem 18 Let $(X, d)$ be a complete generalized metric space, $\alpha: X \times X \rightarrow \mathbb{R}$ be a function, and let $T: X \rightarrow X$ be a map. Suppose that the following conditions are satisfied:

(1) $T$ is a generalized $\alpha-\psi$-Geraghty contraction mapping;

(2) $T$ is triangular $\alpha$-admissible;

(3) there exists $x_{0} \in X$ such that $\alpha\left(x_{0}, T x_{0}\right) \geq 1$ and $\alpha\left(x_{0}, T^{2} x_{0}\right) \geq 1$;

(4) $T$ is continuous.

Then $T$ has a fixed point $x^{*} \in X$, and $\left\{T^{n} x_{0}\right\}$ converges to $x^{*}$.

Proof By (3) let $x_{0} \in X$, construct the sequence $\left\{x_{n}\right\}$ as $x_{n+1}=T x_{n}, n \in \mathbb{N}$. If $x_{n}=x_{n+1}$ for some $n \in \mathbb{N} \cup\{0\}$, then $x^{*}=x_{n}$ is a fixed point of $T$. Assume further that $x_{n} \neq x_{n+1}$ for each $n \in \mathbb{N} \cup\{0\}$. Since $T$ is triangular $\alpha$-admissible, it follows from (3) that

$$
\alpha\left(x_{1}, x_{2}\right)=\alpha\left(x_{1}, T x_{1}\right) \geq 1 \quad \text { and } \quad \alpha\left(x_{1}, x_{3}\right)=\alpha\left(x_{1}, T^{2} x_{1}\right) \geq 1 .
$$

So by induction we get

$$
\alpha\left(x_{n}, x_{n+1}\right) \geq 1 \quad \text { and } \quad \alpha\left(x_{n}, x_{n+2}\right) \geq 1
$$

for $n \in \mathbb{N}$. And we also find $\alpha\left(x_{n}, x_{n+m}\right) \geq 1$ for each $m, n \in \mathbb{N}$.

Therefore, by (3.17)

$$
\begin{aligned}
\psi\left(d\left(x_{n}, x_{n+1}\right)\right) & \leq \alpha\left(x_{n-1}, x_{n}\right) \psi\left(d\left(T x_{n-1}, T x_{n}\right)\right) \\
& \leq \beta\left(\psi\left(M\left(x_{n-1}, x_{n}\right)\right)\right) \psi\left(M\left(x_{n-1}, x_{n}\right)\right) \\
& <\psi\left(M\left(x_{n-1}, x_{n}\right)\right)
\end{aligned}
$$


for each $n \geq 1$, where

$$
\begin{aligned}
M\left(x_{n-1}, x_{n}\right) & =\max \left\{d\left(x_{n-1}, x_{n}\right), d\left(x_{n-1}, x_{n}\right), d\left(x_{n}, x_{n+1}\right)\right\} \\
& =\max \left\{d\left(x_{n-1}, x_{n}\right), d\left(x_{n}, x_{n+1}\right)\right\} .
\end{aligned}
$$

If $\max \left\{d\left(x_{n-1}, x_{n}\right), d\left(x_{n}, x_{n+1}\right)\right\}=d\left(x_{n}, x_{n+1}\right)$, then by (3.19) we get

$$
\psi\left(d\left(x_{n}, x_{n+1}\right)\right)<\psi\left(d\left(x_{n}, x_{n+1}\right)\right)
$$

which is a contradiction. Hence $\max \left\{d\left(x_{n-1}, x_{n}\right), d\left(x_{n}, x_{n+1}\right)\right\}=d\left(x_{n-1}, x_{n}\right)$, therefore (3.19) gives

$$
\psi\left(d\left(x_{n}, x_{n+1}\right)\right)<\psi\left(d\left(x_{n-1}, x_{n}\right)\right) \quad \text { for all } n \in \mathbb{N} .
$$

This yields that for each $n \in \mathbb{N}$,

$$
d\left(x_{n}, x_{n+1}\right)<d\left(x_{n-1}, x_{n}\right) .
$$

Thus, we conclude that the sequence $\left\{d\left(x_{n}, x_{n+1}\right)\right\}$ is nonnegative and nonincreasing. As a result, there exists $t \geq 0$ such that $\lim _{n \rightarrow \infty} d\left(x_{n}, x_{n+1}\right)=t$. We claim that $t=0$. Suppose, on the contrary, that $t>0$. Then, on account of (3.19), we get that

$$
\frac{\psi\left(d\left(x_{n}, x_{n+1}\right)\right)}{\psi\left(M\left(x_{n-1}, x_{n}\right)\right)} \leq \beta\left(\psi\left(M\left(x_{n-1}, x_{n}\right)\right)\right)<1,
$$

which yields that $\lim _{n \rightarrow \infty} \beta\left(\psi\left(d\left(x_{n}, x_{n+1}\right)\right)\right)=1$. We derive

$$
\lim _{n \rightarrow \infty} \psi\left(d\left(x_{n}, x_{n+1}\right)\right)=0 \text {, }
$$

due to the fact that $\beta \in \mathcal{F}$. On the other hand, the continuity of $\psi$ together with (3.23) yields that

$$
\lim _{n \rightarrow \infty} d\left(x_{n}, x_{n+1}\right)=0 .
$$

Now, we shall show

$$
\lim _{n \rightarrow \infty} d\left(x_{n}, x_{n+2}\right)=0 .
$$

Regarding (3.17) and (3.18), we find that

$$
\begin{aligned}
\psi\left(d\left(x_{n}, x_{n+2}\right)\right) & \leq \alpha\left(x_{n-1}, x_{n+1}\right) \psi\left(d\left(T x_{n-1}, T x_{n+1}\right)\right) \\
& \leq \beta\left(\psi\left(M\left(x_{n-1}, x_{n+1}\right)\right)\right) \psi\left(M\left(x_{n-1}, x_{n+1}\right)\right) \\
& <\psi\left(M\left(x_{n-1}, x_{n+1}\right)\right)
\end{aligned}
$$

for all $n \in \mathbb{N}$, where

$$
\begin{aligned}
M\left(x_{n-1}, x_{n+1}\right) & =\max \left\{d\left(x_{n-1}, x_{n+1}\right), d\left(x_{n-1}, T x_{n-1}\right), d\left(x_{n+1}, T x_{n+1}\right)\right\} \\
& =\max \left\{d\left(x_{n-1}, x_{n+1}\right), d\left(x_{n-1}, x_{n}\right), d\left(x_{n+1}, x_{n+2}\right)\right\} .
\end{aligned}
$$


In view of (3.22), we obtain

$$
M\left(x_{n-1}, x_{n+1}\right)=\max \left\{d\left(x_{n-1}, x_{n+1}\right), d\left(x_{n-1}, x_{n}\right)\right\} .
$$

Define $a_{n}=d\left(x_{n}, x_{n+2}\right)$ and $b_{n}=d\left(x_{n}, x_{n+1}\right)$. Then, taking (3.26) into account, we get

$$
\psi\left(a_{n}\right)<\psi\left(\max \left\{a_{n-1}, b_{n-1}\right\}\right) .
$$

This yields that for each $n \in \mathbb{N}$,

$$
a_{n}<\max \left\{a_{n-1}, b_{n-1}\right\} .
$$

In the light of (3.22), we have

$$
b_{n}<\max \left\{a_{n-1}, b_{n-1}\right\} .
$$

Therefore

$$
\max \left\{a_{n}, b_{n}\right\}<\max \left\{a_{n-1}, b_{n-1}\right\} \quad \text { for all } n \in \mathbb{N} \text {. }
$$

Thus, the sequence $\max \left\{a_{n}, b_{n}\right\}$ is nonnegative and nonincreasing, so it converges to some $r \geq 0$. Clearly, by (3.24)

$$
\lim _{n \rightarrow \infty} d\left(x_{n}, x_{n+2}\right)=\lim _{n \rightarrow \infty} a_{n}=\lim _{n \rightarrow \infty} \max \left\{a_{n}, b_{n}\right\}=r .
$$

Now we have to show that $r=0$. If to the contrary $r>0$, then in view of (3.26), we have

$$
\frac{\psi\left(d\left(x_{n}, x_{n+2}\right)\right)}{\psi\left(M\left(x_{n-1}, x_{n+1}\right)\right)} \leq \beta\left(\psi\left(M\left(x_{n-1}, x_{n+1}\right)\right)\right)<1,
$$

which yields that $\lim _{n \rightarrow \infty} \beta\left(\psi\left(M\left(x_{n-1}, x_{n+1}\right)\right)\right)=1$. We derive

$$
\lim _{n \rightarrow \infty} \psi\left(M\left(x_{n-1}, x_{n+1}\right)\right)=0
$$

due to the fact that $\beta \in \mathcal{F}$. On the other hand, the continuity of $\psi$ together with (3.30) yields that

$$
\psi(r)=\psi\left(\lim _{n \rightarrow \infty} \max \left\{a_{n-1}, b_{n-1}\right\}\right)=\lim _{n \rightarrow \infty} \psi\left(\max \left\{a_{n-1}, b_{n-1}\right\}\right)=0,
$$

which is a contradiction and hence $r=0$.

Suppose that $x_{n}=x_{m}$ for some $m, n \in \mathbb{N}, m<n$. Then

$$
\begin{aligned}
\psi\left(d\left(x_{m}, x_{m+1}\right)\right) & =\psi\left(d\left(x_{n}, x_{n+1}\right)\right) \\
& \leq \beta\left(\psi\left(M\left(x_{n-1}, x_{n}\right)\right)\right) \psi\left(M\left(x_{n-1}, x_{n}\right)\right) \\
& <\psi\left(d\left(x_{n-1}, x_{n}\right)\right) \leq \psi^{n-m}\left(d\left(x_{m}, x_{m+1}\right)\right) \\
& <\psi\left(d\left(x_{m}, x_{m+1}\right)\right)
\end{aligned}
$$

a contradiction. Hence, all elements of the sequence $\left\{x_{n}\right\}$ are distinct. 
In order to prove that $\left\{x_{n}\right\}$ is a Cauchy sequence in $(X, d)$, suppose that it is not. Then by Lemma 6, using (3.24) and (3.25), we assert that there exist $\epsilon>0$ and two sequences $\left\{m_{k}\right\}$ and $\left\{n_{k}\right\}$ of positive integers such that $n_{k}>m_{k}>k$ and sequences given in (2.2) tends to $\epsilon$ as $k \rightarrow \infty$. By substituting $x=x_{m_{k}}$ and $y=x_{n_{k+1}}$ in (3.17) and taking (3.18) into account, we obtain

$$
\begin{aligned}
\psi\left(d\left(x_{m_{k}}, x_{n_{k+1}}\right)\right) & \leq \alpha\left(x_{m_{k-1}}, x_{n_{k}}\right) \psi\left(d\left(T x_{m_{k-1}}, T x_{n_{k}}\right)\right) \\
& \leq \beta\left(\psi\left(M\left(x_{m_{k-1}}, x_{n_{k}}\right)\right)\right) \psi\left(M\left(x_{m_{k-1}}, x_{n_{k}}\right)\right) .
\end{aligned}
$$

On the other hand, we have

$$
\begin{aligned}
M\left(x_{m_{k-1}}, x_{n_{k}}\right) & =\max \left\{d\left(x_{m_{k-1}}, x_{n_{k}}\right), d\left(x_{m_{k-1}}, T x_{m_{k-1}}\right), d\left(x_{n_{k}}, T x_{n_{k}}\right)\right\} \\
& =\max \left\{d\left(x_{m_{k-1}}, x_{n_{k}}\right), d\left(x_{m_{k-1}}, x_{m_{k}}\right), d\left(x_{n_{k}}, x_{n_{k+1}}\right)\right\},
\end{aligned}
$$

and hence

$$
\lim _{k \rightarrow \infty} \psi\left(M\left(x_{m_{k-1}}, x_{n_{k}}\right)\right)=\psi(\epsilon) .
$$

From (3.31) we have

$$
\frac{\psi\left(d\left(x_{m_{k}}, x_{n_{k+1}}\right)\right)}{\psi\left(M\left(x_{m_{k-1}}, x_{n_{k}}\right)\right)} \leq \beta\left(\psi\left(M\left(x_{m_{k-1}}, x_{n_{k}}\right)\right)\right)<1 .
$$

Letting $k \rightarrow \infty$, it follows that

$$
\lim _{k \rightarrow \infty} \beta\left(\psi\left(M\left(x_{m_{k-1}}, x_{n_{k}}\right)\right)\right)=1 .
$$

Thus, $\lim _{k \rightarrow \infty} \psi\left(M\left(x_{m_{k-1}}, x_{n_{k}}\right)\right)=0$ and hence (3.33) gives $\psi(\epsilon)=0$, which is a contradiction. Therefore, $\left\{x_{n}\right\}$ is a Cauchy sequence. Since $(X, d)$ is a complete generalized metric space, there exists $x^{*} \in X$ such that $\lim _{n \rightarrow \infty} d\left(x_{n}, x^{*}\right)=0$. As $T$ is continuous, therefore we have

$$
\lim _{n \rightarrow \infty} d\left(T x_{n}, x^{*}\right)=\lim _{n \rightarrow \infty} d\left(x_{n+1}, T x^{*}\right)=0 .
$$

By Lemma 5, we get that $T x^{*}=x^{*}$.

If we take $\psi(t)=t$ in Theorem 18 , we get the following.

Corollary 19 Let $(X, d)$ be a complete generalized metric space, $\alpha: X \times X \rightarrow \mathbb{R}$ be a function, and let $T: X \rightarrow X$ be a map. Suppose that the following conditions are satisfied:

(1) $T$ is a generalized $\alpha$-Geraghty contraction mapping;

(2) $T$ is triangular $\alpha$-admissible;

(3) there exists $x_{0} \in X$ such that $\alpha\left(x_{0}, T x_{0}\right) \geq 1$ and $\alpha\left(x_{0}, T^{2} x_{0}\right) \geq 1$;

(4) $T$ is continuous.

Then $T$ has a fixed point $x^{*} \in X$, and $\left\{T^{n} x_{0}\right\}$ converges to $x^{*}$. 
Theorem 20 Let $(X, d)$ be a complete generalized metric space, $\alpha: X \times X \rightarrow \mathbb{R}$ be a function, and let $T: X \rightarrow X$ be a map. Suppose that the following conditions are satisfied:

(1) $T$ is a generalized $\alpha-\psi$-Geraghty contraction mapping;

(2) $T$ is triangular $\alpha$-admissible;

(3) there exists $x_{0} \in X$ such that $\alpha\left(x_{0}, T x_{0}\right) \geq 1$ and $\alpha\left(x_{0}, T^{2} x_{0}\right) \geq 1$;

(4) $\left\{x_{n}\right\}$ is $\alpha$-regular.

Then $T$ has a fixed point $x^{*} \in X$, and $\left\{T^{n} x_{0}\right\}$ converges to $x^{*}$.

Proof Following the proof of Theorem 18, we know that the sequence $\left\{x_{n}\right\}$ defined by $x_{n+1}=T x_{n}$ for all $n \geq 0$, converges to some $x^{*} \in X$. Now, we shall show that $T x^{*}=x^{*}$. Suppose, on the contrary, that $T x^{*} \neq x^{*}$, i.e., $d\left(x^{*}, T x^{*}\right)>0$. Since $x_{n}$ is $\alpha$-regular, then from (3.18) there exists a subsequence $\left\{x_{n_{k}}\right\}$ of $\left\{x_{n}\right\}$ such that $\alpha\left(x_{n_{k}}, x^{*}\right) \geq 1$. Applying (3.17), for all $k$, we get that

$$
\begin{aligned}
\psi\left(d\left(x_{n_{k+1}}, T x^{*}\right)\right) & \leq \alpha\left(x_{n_{k}}, x^{*}\right) \psi\left(d\left(T x_{n_{k}}, T x^{*}\right)\right) \\
& \leq \beta\left(\psi\left(M\left(x_{n_{k}}, x^{*}\right)\right)\right) \psi\left(M\left(x_{n_{k}}, x^{*}\right)\right) \\
& <\psi\left(M\left(x_{n_{k}}, x^{*}\right)\right),
\end{aligned}
$$

where $M\left(x_{n_{k}}, x^{*}\right)=\max \left\{d\left(x_{n_{k}}, x^{*}\right), d\left(x_{n_{k}}, T x_{n_{k}}\right), d\left(x^{*}, T x^{*}\right)\right\}$.

After letting $k \rightarrow \infty$ in (3.34), we have

$$
\lim _{n \rightarrow \infty} \psi\left(d\left(x_{n_{k+1}}, T x^{*}\right)\right)<\psi\left(d\left(x^{*}, T x^{*}\right)\right) .
$$

In view of Proposition 7, we get a contradiction and hence $x^{*}=T x^{*}$.

Corollary 21 Let $(X, d)$ be a complete generalized metric space, $\alpha: X \times X \rightarrow \mathbb{R}$ be a function, and let $T: X \rightarrow X$ be a map. Suppose that the following conditions are satisfied:

(1) $T$ is a generalized $\alpha$-Geraghty contraction mapping;

(2) $T$ is triangular $\alpha$-admissible;

(3) there exists $x_{0} \in X$ such that $\alpha\left(x_{0}, T x_{0}\right) \geq 1$ and $\alpha\left(x_{0}, T^{2} x_{0}\right) \geq 1$;

(4) $\left\{x_{n}\right\}$ is $\alpha$-regular.

Then $T$ has a fixed point $x^{*} \in X$, and $\left\{T^{n} x_{0}\right\}$ converges to $x^{*}$.

For the uniqueness of a fixed point of $\alpha-\psi$-Geraghty contraction and generalized $\alpha-\psi$ Geraghty contraction mapping, we will consider the following condition.

(U): For all $x, y \in F(T)$, we have $\alpha(x, y) \geq 1$, where $F(T)$ denotes the set of fixed points of $T$.

Theorem 22 Adding condition (U) to the hypothesis of Theorem 12 (respectively, Theorem 15), we obtain that $u$ is the unique fixed point of $T$.

Proof We have to show that $u$ is a unique fixed point of $T$. Let $v$ be another fixed point of $T$ with $v \neq u$. By hypothesis (U),

$$
1 \leq \alpha(u, v)=\alpha(T u, T v)
$$


Now, using (3.1), we have

$$
\begin{aligned}
\psi(d(u, v)) & \leq \alpha(u, v) \psi(d(T u, T v)) \\
& \leq \beta(\psi(d(u, v))) \psi(d(u, v)) \\
& <\psi(d(u, v))
\end{aligned}
$$

which is a contradiction. Hence, $u=v$.

Theorem 23 Adding condition (U) to the hypothesis of Theorem 18 (respectively, Theorem 20), we obtain that $u$ is the unique fixed point of $T$.

Proof As we have done in the proof of Theorem 22. Let $v$ be another fixed point of $T$ with $v \neq u$. Then, by assumption (U), we get

$$
1 \leq \alpha(u, v)=\alpha(T u, T v)
$$

Now, using (3.17), we have

$$
\begin{aligned}
\psi(d(u, v)) & \leq \alpha(u, v) \psi(d(T u, T v)) \\
& \leq \beta(\psi(M(u, v))) \psi(M(u, v)) \\
& <\psi(M(u, v))
\end{aligned}
$$

where

$$
M(u, v)=\max \{d(u, v), d(u, T u), d(v, T v)\} .
$$

Therefore,

$$
\psi(d(u, v))<\psi(d(u, v))
$$

which is a contradiction. Hence, $u=v$.

Theorem 24 Adding condition (U) to the hypothesis of Corollary 13 (respectively, Corollary 16, Corollary 19 and Corollary 21), we obtain that $u$ is the unique fixed point of $T$.

\section{Consequences}

If we define the mapping $\alpha: X \times X \rightarrow[0, \infty)$ by $\alpha(x, y)=1$ for all $x, y \in X$, then, by Theorem 22 and Theorem 23, we obtain the following corollary as an extension of several known results in the literature.

Corollary 25 Let $(X, d)$ be a complete generalized metric space and $T: X \rightarrow X$ be a map. Assume that there exist two functions $\beta \in \mathcal{F}$ and $\psi \in \Psi$ such that

$$
\psi(d(T x, T y)) \leq \beta(\psi(d(x, y))) \psi(d(x, y))
$$

for all $x, y \in X$. Then $T$ has a unique fixed point. 
Corollary 26 Let $(X, d)$ be a complete generalized metric space and $T: X \rightarrow X$ be a map. Assume that there exist two functions $\beta \in \mathcal{F}$ and $\psi \in \Psi$ such that, for all $x, y \in X$,

$$
\psi(d(T x, T y)) \leq \beta(\psi(M(x, y))) \psi(M(x, y))
$$

where $M(x, y)=\max \{d(x, y), d(x, T x), d(y, T y)\}$. Then $T$ has a unique fixed point.

If we let $\psi(t)=t$, we get the following two corollaries.

Corollary 27 Let $(X, d)$ be a complete generalized metric space and $T: X \rightarrow X$ be a map. Assume that there exists a function $\beta \in \mathcal{F}$ such that

$$
d(T x, T y) \leq \beta(d(x, y)) d(x, y)
$$

for all $x, y \in X$. Then $T$ has a unique fixed point.

Corollary 28 Let $(X, d)$ be a complete generalized metric space and $T: X \rightarrow X$ be a map. Assume that there exists a function $\beta \in \mathcal{F}$ such that, for all $x, y \in X$,

$$
d(T x, T y) \leq \beta(M(x, y)) M(x, y)
$$

where $M(x, y)=\max \{d(x, y), d(x, T x), d(y, T y)\}$. Then $T$ has a unique fixed point.

\subsection{Fixed point theorems on metric spaces endowed with a partial order}

In this section, we state some consequences of our main results in the context of a partially ordered metric space.

Definition 29 Let $(X, \preceq)$ be a partially ordered set and $T: X \rightarrow X$ be a given mapping. We say that $T$ is nondecreasing with respect to $\preceq$ if

$$
x, y \in X, \quad x \preceq y \quad \Rightarrow \quad T x \preceq T y .
$$

Definition 30 Let $(X, \preceq)$ be a partially ordered set. A sequence $\left\{x_{n}\right\} \subset X$ is said to be nondecreasing with respect to $\preceq$ if $x_{n} \preceq x_{n+1}$ for all $n$.

Definition 31 Let $(X, \preceq)$ be a partially ordered set and $d$ be a metric on $X$. We say that $(X, \preceq, d)$ is regular if for every nondecreasing sequence $\left\{x_{n}\right\} \subset X$ such that $x_{n} \rightarrow x \in X$ as $n \rightarrow \infty$, there exists a subsequence $\left\{x_{n_{k}}\right\}$ of $\left\{x_{n}\right\}$ such that $x_{n_{k}} \preceq x$ for all $k$.

We have the following result.

Corollary 32 Let $(X, \preceq)$ be a partially ordered set and $d$ be a generalized metric on $X$ such that $(X, d)$ is complete. Let $T: X \rightarrow X$ be a nondecreasing mapping with respect to $\preceq$. Suppose that there exists a function $\psi \in \Psi$ such that

$$
\psi(d(T x, T y)) \leq \beta(\psi(M(x, y))) \psi(M(x, y))
$$

for all $x, y \in X$ with $x \geq y$. Suppose also that the following conditions hold: 
(i) there exists $x_{0} \in X$ such that $x_{0} \preceq T x_{0}$;

(ii) $T$ is continuous or $(X, \preceq, d)$ is regular.

Then $T$ has a fixed point. Moreover, if for all $x, y \in X$ there exists $z \in X$ such that $x \preceq z$ and $y \preceq z$, we have uniqueness of the fixed point.

Proof Let $\alpha: X \times X \rightarrow[0, \infty)$ be a mapping defined by

$$
\alpha(x, y)= \begin{cases}1 & \text { if } x \leq y \text { or } x \geq y \\ 0 & \text { otherwise }\end{cases}
$$

Notice that $T$ is a generalized $\alpha-\psi$-Geraghty contraction mapping, that is,

$$
\alpha(x, y) \psi(d(T x, T y)) \leq \beta(\psi(M(x, y))) \psi(M(x, y))
$$

for all $x, y \in X$. Due to (i), we have $\alpha\left(x_{0}, T x_{0}\right) \geq 1$. Owing to the monotone property of $T$, we observe that

$$
\begin{aligned}
& \alpha(x, y) \geq 1 \quad \Rightarrow \quad x \geq y \quad \text { or } \quad x \preceq y \quad \Rightarrow \quad T x \geq T y \quad \text { or } \\
& T x \preceq T y \Rightarrow \alpha(T x, T y) \geq 1
\end{aligned}
$$

for all $x, y \in X$. Hence, $T$ is $\alpha$-admissible. It is evident from Theorem 12 that $T$ has a fixed point if it is continuous. Let us discuss the case that $(X, \preceq, d)$ is regular. Let $\left\{x_{n}\right\}$ be a sequence in $X$ such that $\alpha\left(x_{n}, x_{n+1}\right) \geq 1$ for all $n$ and $x_{n} \rightarrow x \in X$ as $n \rightarrow \infty$. From the regularity hypothesis, there exists a subsequence $\left\{x_{n_{k}}\right\}$ of $\left\{x_{n}\right\}$ such that $x_{n_{k}} \preceq x$ for all $k$. The definition of $\alpha$ yields that $\alpha\left(x_{n_{k}}, x\right) \geq 1$ for all $k$. In this case, the existence of a fixed point follows from Theorem 15. The uniqueness follows from Theorem 18.

The following results are immediate consequences of Corollary 32.

Corollary 33 Let $(X, \preceq)$ be a partially ordered set and $d$ be a generalized metric on $X$ such that $(X, d)$ is complete. Let $T: X \rightarrow X$ be a nondecreasing mapping with respect to $\preceq$. Suppose that there exists a function $\psi \in \Psi$ such that

$$
\psi(d(T x, T y)) \leq \beta(\psi(d(x, y))) \psi(d(x, y))
$$

for all $x, y \in X$ with $x \geq y$. Suppose also that the following conditions hold:

(i) there exists $x_{0} \in X$ such that $x_{0} \preceq T x_{0}$;

(ii) $T$ is continuous or $(X, \preceq, d)$ is regular.

Then $T$ has a fixed point. Moreover, if for all $x, y \in X$ there exists $z \in X$ such that $x \preceq z$ and $y \preceq z$, we have uniqueness of the fixed point.

The following two corollaries can be concluded from the above results by taking $\psi(t)=t$.

Corollary 34 Let $(X, \preceq)$ be a partially ordered set and $d$ be a generalized metric on $X$ such that $(X, d)$ is complete. Let $T: X \rightarrow X$ be a nondecreasing mapping with respect to $\preceq$. Suppose that there exists a function $\psi \in \Psi$ such that

$$
d(T x, T y) \leq \beta(M(x, y)) M(x, y)
$$


for all $x, y \in X$ with $x \geq y$. Suppose also that the following conditions hold:

(i) there exists $x_{0} \in X$ such that $x_{0} \preceq T x_{0}$;

(ii) $T$ is continuous or $(X, \preceq, d)$ is regular.

Then $T$ has a fixed point. Moreover, iffor all $x, y \in X$ there exists $z \in X$ such that $x \preceq z$ and $y \preceq z$, we have uniqueness of the fixed point.

Corollary 35 Let $(X, \preceq)$ be a partially ordered set and $d$ be a generalized metric on $X$ such that $(X, d)$ is complete. Let $T: X \rightarrow X$ be a nondecreasing mapping with respect to $\preceq$. Suppose that there exists a function $\psi \in \Psi$ such that

$$
d(T x, T y) \leq \beta(d(x, y)) d(x, y)
$$

for all $x, y \in X$ with $x \geq y$. Suppose also that the following conditions hold:

(i) there exists $x_{0} \in X$ such that $x_{0} \preceq T x_{0}$;

(ii) $T$ is continuous or $(X, \preceq, d)$ is regular.

Then $T$ has a fixed point. Moreover, iffor all $x, y \in X$ there exists $z \in X$ such that $x \preceq z$ and $y \preceq z$, we have uniqueness of the fixed point.

In [49] Haghi et al. proved the following lemma.

Lemma 36 Let $X$ be a nonempty set and $f: X \rightarrow X$ be a function. Then there exists a subset $E \subseteq X$ such that $f(E)=f(X)$ and $f: E \rightarrow X$ is one to one.

Theorem 37 Let $(X, d)$ be a generalized metric space, and let $T, f: X \rightarrow X$ be two selfmaps such that $T(X) \subseteq f(X)$ and $f(X)$ is a complete subset of $X$. If there exist two functions $\beta \in \mathcal{F}$ and $\psi \in \Psi$ such that

$$
\psi(d(T x, T y)) \leq \beta(\psi(d(f x, f y))) \psi(d(f x, f y))
$$

holds for all $x, y \in X$, then $T$ and $f$ have a unique point of coincidence in $X$. Moreover, if $T$ and $f$ are weakly compatible, then $T$ and $f$ have a unique common fixed point.

Proof By Lemma 36, there exists $E \subseteq X$ such that $f(E)=f(X)$ and $f: E \rightarrow X$ is one to one. We define a map $g: f(E) \rightarrow f(E)$ by $g(f x)=T x$. Clearly, $g$ is well defined, since $f$ is one to one. Now, using (4.5), we have

$$
\begin{aligned}
\psi(d(g(f x), g(f y))) & =\psi(d(T x, T y)) \\
& \leq \beta(\psi(d(f x, f y))) \psi(d(f x, f y))
\end{aligned}
$$

for all $f x, f y \in f(E)$. Since $f(E)=f(X)$ is complete, therefore by Corollary 25 there exists $z \in X$ such that $g(f z)=f z$, which implies $T z=f z$. Hence, $T$ and $f$ have a coincidence point. Again, if $w$ is another coincidence point of $T$ and $f$ such that $z \neq w$, then by (4.5)

$$
\begin{aligned}
\psi(d(T w, T z)) & \leq \beta(\psi(d(f w, f z))) \psi(d(f w, f z)) \\
& <\psi(d(T w, T z)),
\end{aligned}
$$

which is a contradiction. Hence $z$ is a unique coincidence point of $T$ and $f$. It is clear that $T$ and $f$ have a unique common fixed point whenever $T$ and $f$ are weakly compatible. 
Theorem 38 Let $(X, d)$ be a generalized metric space, and let $T, f: X \rightarrow X$ be two selfmaps such that $T(X) \subseteq f(X)$ and $f(X)$ is a complete subset of $X$. If there exist two functions $\beta \in \mathcal{F}$ and $\psi \in \Psi$ such that, for all $x, y \in X$,

$$
\psi(d(T x, T y)) \leq \beta(\psi(M(f x, f y))) \psi(M(f x, f y))
$$

where $M(x, y)=\max \{d(f x, f y), d(f x, T x), d(f y, T y)\}$. Then $T$ and $f$ have a unique point of coincidence in $X$. Moreover, if $T$ and $f$ are weakly compatible, then $T$ and $f$ have a unique common fixed point.

Proof Here, we utilize Corollary 26 instead of Corollary 25 in the proof of Theorem 37 and the proof completely follows the lines of the proof of Theorem 37 and hence it is omitted.

Now, in support of the proved results, we present an example which is inspired by Example 4.11 of [50].

Example 39 Let $X=\{\alpha, \beta, \gamma, \delta\}$ and define $d: X \times X \rightarrow[0, \infty)$ by

$$
\begin{array}{ll}
d(\alpha, \beta)=d(\beta, \alpha)=0.2, & d(\alpha, \gamma)=d(\gamma, \alpha)=1, \\
d(\alpha, \delta)=d(\delta, \alpha)=0.8, & d(\beta, \gamma)=d(\gamma, \beta)=0.5, \\
d(\beta, \delta)=d(\delta, \beta)=1.2, & d(\gamma, \delta)=d(\delta, \gamma)=0.9, \\
d(\alpha, \alpha)=d(\beta, \beta)=d(\gamma, \gamma)=d(\delta, \delta)=0 .
\end{array}
$$

Then it can be easily checked that $(X, d)$ is a generalized metric space which is not a metric space since the inequality

$$
1=d(\alpha, \gamma) \leq d(\alpha, \beta)+d(\beta, \gamma)=0.7
$$

is not true. Define $T: X \rightarrow X$

$$
T(x)= \begin{cases}\beta & \text { if } x \neq \gamma \\ \delta & \text { if } x=\gamma\end{cases}
$$

and $\alpha: X \times X \rightarrow[0, \infty)$ by

$$
\alpha(x, y)= \begin{cases}1 & \text { if } x, y \in X-\{\gamma\} \\ \frac{1}{4} & \text { otherwise }\end{cases}
$$

Firstly, we will prove that

(a) $T$ is triangular $\alpha$-admissible;

(b) there exists $x_{0} \in X$ such that $\alpha\left(x_{0}, T x_{0}\right) \geq 1$ and $\alpha\left(x_{0}, T^{2} x_{0}\right) \geq 1$;

(c) $\left\{x_{n}\right\}$ is $\alpha$-regular;

(d) hypothesis (U) is satisfied.

Proof (a) (i) Let $x, y \in X$ such that $\alpha(x, y) \geq 1$. Then, by the definition of $\alpha$, we have $x, y \in$ $X-\{\gamma\}$, therefore $\alpha(T x, T y)=1$. 
(ii) Let $x, y, z \in X$ such that $\alpha(x, z) \geq 1$ and $\alpha(y, z) \geq 1$. Again the definition of $\alpha$ gives $x, y, z \in X-\{\gamma\}$ and hence $\alpha(x, y)=1$.

So, (i) and (ii) imply that $T$ is triangular $\alpha$-admissible.

(b) Taking $x_{0}=\delta$, we have $\alpha\left(x_{0}, T x_{0}\right)=\alpha(\delta, \beta)=1$ and $\alpha\left(x_{0}, T^{2} x_{0}\right)=\alpha(\delta, \beta)=1$.

(c) Let $\left\{x_{n}\right\}$ be a sequence in $X$ such that $\alpha\left(x_{n}, x_{n+1}\right) \geq 1$ for all $n$ and $x_{n} \rightarrow x$ as $n \rightarrow \infty$. By the definition of $\alpha$, for each $n, x_{n} \in X-\{\gamma\}$. Since $X-\{\gamma\}=\{\alpha, \beta, \delta\}$ is closed, we get that $x \in X-\{\gamma\}$. Therefore, the definition of $\alpha$ gives $\alpha\left(x_{n}, x\right)=1$ for each $n \in \mathbb{N}$.

(d) Let $x, y \in F(T)$. Clearly $x=y=\beta$, therefore, by the definition of $\alpha$, we have $\alpha(x, y)=$ $\alpha(\beta, \beta)=1$.

Also, we define $\psi \in \Psi$ by

$$
\psi(t)=\frac{t}{4}, \quad t \in[0, \infty)
$$

and $\beta:[0, \infty) \rightarrow[0,1)$ by

$$
\beta(t)=\frac{1}{1+t} .
$$

Clearly, $\beta \in \mathcal{F}$. Now, we will show that $T$ is an $\alpha-\psi$-Geraghty contraction mapping. Let $x, y \in X$ with $x \neq y$ and consider the following possible cases.

Case 1. If $x, y \in\{\alpha, \beta, \delta\}$, then $d(T x, T y)=d(\beta, \beta)=0$ and hence (3.1) trivially holds.

Case 2. If $x=\gamma, y \in\{\alpha, \beta, \delta\}$, then $d(T x, T y)=d(\delta, \beta)=1.2$.

If $y=\alpha$, then

$$
\begin{aligned}
\beta( & \psi(d(x, y))) \psi(d(x, y))-\alpha(x, y) \psi(d(T x, T y)) \\
& =\beta(\psi(d(\gamma, \alpha))) \psi(d(\gamma, \alpha))-\frac{1}{4} \psi(1.2) \\
& =\beta(\psi(1)) \psi(1)-\frac{1}{4} \psi(1.2)>0 .
\end{aligned}
$$

If $y=\beta$, then

$$
\begin{gathered}
\beta(\psi(d(x, y))) \psi(d(x, y))-\alpha(x, y) \psi(d(T x, T y)) \\
\quad=\beta(\psi(d(\gamma, \beta))) \psi(d(\gamma, \beta))-\frac{1}{4} \psi(1.2) \\
=\beta(\psi(0.5)) \psi(0.5)-\frac{1}{4} \psi(1.2)>0 .
\end{gathered}
$$

If $y=\delta$, then

$$
\begin{gathered}
\beta(\psi(d(x, y))) \psi(d(x, y))-\alpha(x, y) \psi(d(T x, T y)) \\
\quad=\beta(\psi(d(\gamma, \delta))) \psi(d(\gamma, \delta))-\frac{1}{4} \psi(1.2) \\
=\beta(\psi(0.9)) \psi(0.9)-\frac{1}{4} \psi(1.2)>0 .
\end{gathered}
$$

Hence inequality (3.1) is satisfied. 
Case 3. If $x \in\{\alpha, \beta, \delta\}, y=\gamma$. Since $d$ is symmetric, therefore (3.1) holds obviously from Case 2.

So, $T$ is an $\alpha-\psi$-Geraghty contraction mapping. Hence all the conditions of Theorem 22 are satisfied, and consequently $T$ has a unique fixed point. Here $\beta$ is such a point.

\section{Remark 40}

(1) It can be easily checked that the map $T$ defined in Example 39 also satisfies inequality (3.17), that is, $T$ is a generalized $\alpha-\psi$-Geraghty contraction mapping. Hence, Example 39 satisfied all the conditions of Theorem 23. Therefore, Theorem 23 also guarantees the existence and uniqueness of the fixed point of $T$.

(2) It is to be noted that $T$ defined in Example 39 does not satisfy (4.1) at $x=\gamma, y=\alpha$ for any $\psi \in \Psi$ and $\beta \in \mathcal{F}$.

\section{Competing interests}

The authors declare that they have no competing interests.

\section{Authors' contributions}

All authors contributed equally to the writing of this paper. All authors read and approved the final manuscript.

\section{Author details}

${ }^{1}$ Department of Mathematics, Zanjan Branch, Islamic Azad University, Zanjan, Iran. ${ }^{2}$ Department of Mathematics, Atilim University, Incek, Ankara 06836, Turkey. ${ }^{3}$ Nonlinear Analysis and Applied Mathematics Research Group (NAAM), King Abdulaziz University, Jeddah, Saudi Arabia. ${ }^{4}$ Department of Mathematics, Maharshi Dayanand University, Rohtak, Haryana 124001, India. ${ }^{5}$ Department of Mathematics, Govt. College Nagina, Mewat, Haryana 122108, India.

Received: 6 May 2014 Accepted: 7 October 2014 Published: 22 October 2014

\section{References}

1. Branciari, A: A fixed point theorem of Banach-Caccioppoli type on a class of generalized metric spaces. Publ. Math. (Debr.) 57, 31-37 (2000)

2. Samet, B: Discussion on 'A fixed point theorem of Banach-Caccioppoli type on a class of generalized metric spaces' by A. Branciari. Publ. Math. (Debr.) 76(4), 493-494 (2010)

3. Wilson, WA: On semimetric spaces. Am. J. Math. 53(2), 361-373 (1931)

4. Jleli, M, Samet, B: The Kannan's fixed point theorem in a cone rectangular metric space. J. Nonlinear Sci. Appl. 2(3), 161-167 (2009)

5. Kirk, WA, Shahzad, N: Generalized metrics and Caristi's theorem. Fixed Point Theory Appl. 2013, 129 (2013)

6. Kikina, L, Kikina, K: A fixed point theorem in generalized metric space. Demonstr. Math. 46(1), 181-190 (2013)

7. Das, $P$, Lahiri, BK: Fixed point of contractive mappings in generalized metric space. Math. Slovaca 59, 499-504 (2009)

8. Lakzian, H, Samet, B: Fixed points for $(\psi, \varphi)$-weakly contractive mapping in generalized metric spaces. Appl. Math. Lett. 25, 902-906 (2012)

9. Aydi, H, Karapınar, E, Lakzian, H: Fixed point results on the class of generalized metric spaces. Math. Sci. 6, 46 (2012)

10. Bilgili, N, Karapınar, E, Turkoglu, D: A note on common fixed points for $(\psi, \alpha, \beta)$-weakly contractive mappings in generalized metric spaces. Fixed Point Theory Appl. 2013, 287 (2013)

11. Chen, CM, Sun, WY: Periodic points for the weak contraction mappings in complete generalized metric spaces. Fixed Point Theory Appl. 2012, 79 (2012)

12. Erhan, I, Karapınar, E, Sekulić, T: Fixed points of $(\psi, \phi)$ contractions on rectangular metric spaces. Fixed Point Theory Appl. 2012, $138(2012)$

13. Mihet, D: On Kannan fixed point principle in generalized metric spaces. J. Nonlinear Sci. Appl. 2(2), $92-96$ (2009)

14. Samet, B, Vetro, C, Vetro, P: Fixed point theorems for $\alpha$ - $\psi$-contractive type mappings. Nonlinear Anal. 75, $2154-2165$ (2012)

15. Ali, MU, Kamran, T, Karapınar, E: $(\alpha, \psi, \xi)$-Contractive multivalued mappings. Fixed Point Theory Appl. 2014, 7 (2014)

16. Jleli, M, Karapınar, E, Samet, B: Best proximity points for generalized $\alpha$ - $\psi$-proximal contractive type mappings. J. Appl. Math. 2013, Article ID 534127 (2013)

17. Jleli, M, Karapınar, E, Samet, B: Fixed point results for $\alpha-\psi_{\lambda}$-contractions on gauge spaces and applications. Abstr. Appl. Anal. 2013, Article ID 730825 (2013)

18. Karapınar, E, Samet, B: Generalized $\alpha$ - $\psi$-contractive type mappings and related fixed point theorems with applications. Abstr. Appl. Anal. 2012, Article ID 793486 (2012)

19. Mohammadi, B, Rezapour, S, Shahzad, N: Some results on fixed points of $\alpha$ - $\psi$-Ciric generalized multifunctions. Fixed Point Theory Appl. 2013, 24 (2013)

20. Ali, MU, Kamran, T: On $\left(\alpha^{*}, \psi\right)$-contractive multi-valued mappings. Fixed Point Theory Appl. 2013, 137 (2013)

21. Rus, IA: Generalized Contractions and Applications. Cluj University Press, Cluj-Napoca (2001) 
22. Bianchini, RM, Grandolfi, M: Transformazioni di tipo contracttivo generalizzato in uno spazio metrico. Atti Accad. Naz. Lincei, Rend. Cl. Sci. Fis. Mat. Nat. 45, 212-216 (1968)

23. Proinov, PD: A generalization of the Banach contraction principle with high order of convergence of successive approximations. Nonlinear Anal. TMA 67, 2361-2369 (2007)

24. Proinov, PD: New general convergence theory for iterative processes and its applications to Newton Kantorovich type theorems. J. Complex. 26, 3-42 (2010)

25. Berzig, $\mathrm{M}, \mathrm{Karapınar}$, E: Fixed point results for $(\alpha \psi, \beta \phi)$-contractive mappings for a generalized altering distance. Fixed Point Theory Appl. 2013, 205 (2013)

26. Berzig, M, Rus, M: Fixed point theorems for $\alpha$-contractive mappings of Meir-Keeler type and applications. arXiv:1303.5798 [math.GN]

27. Cho, S-H, Bae, J-S, Karapınar, E: Fixed point theorems for $\alpha$-Geraghty contraction type maps in metric spaces. Fixed Point Theory Appl. 2013, 329 (2013)

28. Suzuki, T: Generalized metric spaces do not have the compatible topology. Abstr. Appl. Anal. 2014, Article ID 458098 (2014)

29. Banach, S: Sur les opérations dans les ensembles abstraits et leur applications aux équations intégrales. Fundam. Math. 3, 133-181 (1922)

30. Bilgili, N, Karapınar, E, Sadarangani, K: A generalization for the best proximity point of Geraghty-contractions. J. Inequal. Appl. 2013, 286 (2013)

31. Caballero, J, Harjani, J, Sadarangani, K: A best proximity point theorem for Geraghty-contractions. Fixed Point Theory Appl. 2012, 231 (2012)

32. Cho, S-H, Bae, J-S: Common fixed point theorems for mappings satisfying property (E.A) on cone metric spaces. Math. Comput. Model. 53, 945-951 (2011)

33. Geraghty, M: On contractive mappings. Proc. Am. Math. Soc. 40, 604-608 (1973)

34. Gordji, ME, Ramezani, M, Cho, YJ, Pirbavafa, S: A generalization of Geraghty's theorem in partially ordered metric space and application to ordinary differential equations. Fixed Point Theory Appl. 2012, 74 (2012)

35. Hille, E, Phillips, RS: Functional Analysis and Semi-Groups. Amer. Math. Soc. Colloq. Publ., vol. 31. Am. Math. Soc., Providence (1957)

36. Karapınar, E: On best proximity point of $\psi$-Geraghty contractions. Fixed Point Theory Appl. 2013, 200 (2013)

37. Rhoades, BE: A comparison of various definitions of contractive mappings. Trans. Am. Math. Soc. 226, 257-290 (1977)

38. Kutbi, MA, Sintunavarat, $W$ : The existence of fixed point theorems via $w$-distance and $\alpha$-admissible mappings and applications. Abstr. Appl. Anal. 2013, Article ID 165434 (2013)

39. Sintunavarat, W: Generalized Ulam-Hyers stability, well-posedness and limit shadowing of fixed point problems for $\alpha$ - $\beta$-contraction mapping in metric spaces. Sci. World J. 2014, Article ID 569174 (2014)

40. Kutbi, MA, Sintunavarat, W: Ulam-Hyers stability and well posedness of fixed point problems for $\alpha-\boldsymbol{\gamma}$-contraction mapping in metric spaces. Abstr. Appl. Anal. 2014, Article ID 268230 (2014)

41. Kutbi, MA, Sintunavarat, W: Fixed point theorems for generalized $w_{\alpha}$-contraction multivalued mappings in $\alpha$-complete metric spaces. Fixed Point Theory Appl. 2014, 139 (2014)

42. Karapınar, E, Kumam, P, Salimi, P: On $\alpha$ - $\psi$-Meir-Keeler contractive mappings. Fixed Point Theory Appl. 2013, 94 (2013)

43. Karapınar, E, Samet, B: Generalized $\alpha$ - $\psi$-contractive type mappings and related fixed point theorems with applications. Abstr. Appl. Anal. 2012, Article ID 793486 (2012)

44. Latif, A, Mongkolkeha, C, Sintunavarat, W: Fixed point theorems for generalized $\alpha$ - $\beta$-weakly contraction mappings in metric spaces and applications. Sci. World J. 2014, Article ID 784207 (2014)

45. Salimi, P, Latif, A, Hussain, N: Modified $\alpha-\psi$-contractive mappings with applications. Fixed Point Theory Appl. 2013, 151 (2013)

46. Kadelburg, Z, Radenović, S: Fixed point results in generalized metric spaces without Hausdorff property. Math. Sci. 8, 125 (2014)

47. Karapınar, E: $\alpha-\psi$-Geraghty contraction type mappings and some related fixed point results. Filomat 28(1), 37-48 (2014)

48. Yang, S-K, Bae, J-S, Cho, S-H: Coincidence and common fixed and periodic point theorems in cone metric spaces. Comput. Math. Appl. 61, 170-177 (2011)

49. Haghi, RH, Rezapour, S, Shazad, N: Some fixed point generalizations are not real generalizations. Nonlinear Anal. 74 , 1799-1803 (2011)

50. Rathee, S, Kumar, A: Some common fixed point and invariant approximation results with generalized almost contractions. Fixed Point Theory Appl. 2014, 23 (2014)

doi:10.1186/1029-242X-2014-423

Cite this article as: Asadi et al.: $\alpha-\psi$-Geraghty contractions on generalized metric spaces. Journal of Inequalities and Applications 2014 2014:423. 